\title{
The Innovation and Exploration of the General Education Curriculum "Automobile Culture"
}

\author{
Guanqiang Ruan, Zhongdong Lu, Jinrun Cheng \\ Shanghai Dianji University, Automobile School \\ Shanghai 201306
}

\begin{abstract}
To comply with the trend of social development, meet the requirement for automotive knowledge and culture, develop the scientific and cultural qualities of college students, we had defined new aim and taken innovation, in this paper, for the general education curriculum "Automobile Culture" in Shanghai Dianji University. Based on the teaching practice of this course, the teaching goal, content update, teaching methods and assessment methods in the curriculum teaching system had been reformed and explored comprehensively. Eminently we adopted the mode of "theme preaches" to improve students' enthusiasm to participate in class teaching. The teaching results suggest that the new teaching system had cultivated students' ability of autonomous learning and team cooperation, improved students' interest and engagement in class, proved the scientificity and availability of the curriculum innovation.
\end{abstract}

Keywords-automobile culture; general education curriculum; teaching innovation; Exploration

\section{INTRODUCTION}

Since the first automobile, Benz 1, was invented in 1886 , the history of automobile has just passed 130 years, while the rapid development of automobile technology has deeply influenced and changed people's life [1]. The automobile has been popularized as people's daily transport from luxury goods which symbolize identity and status, and has closely connect with people's life. The "Automobile Culture" refers to the total of material wealth and spiritual wealth formed in the process of automobile invention, design, production and usage [2]. The formation of a set of behaviors, customs, regulations and values, etc., with vehicle as the carrier, constitute the automobile culture, influencing the people's way of thinking and behavior in all aspects.

At present, numerous colleges have offered "Automobile Culture" general education course, to popularize automobile knowledge and improve the scientific and cultural quality of college students. Based on the Shanghai Dianji University "automobile culture" curriculum construction project, the teaching practice had been explored, and the comprehensive innovation and analysis had been carried on the teaching goal, teaching content update, teaching methods and examination system.

\section{THE AIM OF CURRICULUM CONSTRUCTION}

China's automobile market has grown very rapidly since 2000 , and in 2010, it exploded in total, overtaken the US as the world's largest automobile market. In 2016, China had produced and sold vehicles both more than 28 million [3], and got the first place in the world for eight years consecutively as a veritable automobile country. With the rapid development of the automobile industry in recent decades, numerous colleges have established majors in relation to automobile, to cultivate talents for the growing automobile industry. Investigation indicates that in vocational colleges, the "automobile culture" general education curriculum mainly introduced automotive knowledge, with interest as the guidance, through a variety of teaching methods; cultivated students' interest in automobile and automobile industry [4]. Shanghai Dianji University has offered "automobile culture" general education course to all undergraduates over 3 years, the students are from majors of electrical, machinery, automobile, electronic information, economic management, foreign language etc., while students' academic background is properly different. Therefore, in addition to popularizing automobile knowledge, "automobile culture" can improve the development of students' own quality.

Based on the requirements of Shanghai Dianji University "Automobile Culture" curriculum construction, the aim of the curriculum is established: to popularize the basic automotive knowledge, to broaden students' knowledge range, to improve the scientific level of the students of humanities, to develop the humanities culture quality of the students in science and engineering majors, to achieve the education with combination of the science and humanities culture quality; Promoting the popularization of advanced automobile culture education, meeting people's requirement for basic knowledge such as automotive structure, usage and maintenance, popularizing traffic safety education, advocating civilized manners, and further digging into the automobile cultural connotation consist of technological innovation, motor racing, automobile repacking, safety protection and automobile aesthetics.

\section{THE EXISTING DEFICIENCIES AND IMPROVING MEASURES IN THE CURRICULUM TEACHING SYSTEM}

\section{A. Teaching content: the contents are massive, the update is fast, a fixed textbook is single and cannot meet the teaching demand}

Because of the limitation of the periods, in most "Automobile Culture" textbooks, the contents are relatively thin and outdated, which mainly consist of automotive structure, developing history, famous auto makers and logo, 
classical cars, motor sports, modern automobile technology and so on [5]. These contents are too numerous and monotonous to narrate every subject vividly and enjoyably.

With the convenience of Internet, some students are very familiar with car brand, appearance, configuration information. Comparatively speaking, the contents of the textbook generally have great lag. Therefore, the contents of textbook cannot satisfy the young students' desire to acquire more fresh knowledge of automobile.

Meanwhile, some students, especially girls of liberal arts, nearly have no conception of automotive science and technology, now people's life is closely related to the vehicle, therefore, in addition to popularize knowledge of auto, the curriculum also need to inspire students like automotive culture and advocate automobile civilization, etc.

The undergraduate teaching should pay further attention to the cultivation of students' ability to learn, so it is not necessary to specify a certain textbook. Teachers should guide students to gather information from library or Internet, to achieve knowledge with active thinking. Teachers and students can jointly set up a shared "subjects database" (text, picture, audio, video etc.), which is convenient for students to refer.

The collection of teaching materials is classified into three sections:

(1) Basic knowledge of automobile. This section mainly introduces the structure, principles, design and manufacture of automobile. The structure and function of modern automobile is much more complicated than that of the early vehicles, involving various fields, such as mechanical, electrical, electronic, chemical, etc., which are of strong specialization. With the development of technology, some structure of automobile had been gradually eliminated in the process of evolution, while some of which have been retained as standard.

(2) Vehicle brands. This section includes the developing history of automobile manufacturers, classic models, legendary experiences of the founders, etc., which is most easily understood and interested by students. It is worth mentioning that developed automobile producers because of their different national features, the design and manufacture of automobile is markedly of different technical focus, such as: American prefer muscle High-powered cars, German cars focus on advanced science and technology, the Japanese focus on economic and durable, and so on.

(3) The automobile and society, this section is relatively macroscopical and has rich connotation, including automobile fashion, automobile show, automobile sports, traffic safety, energy crisis, intelligent vehicle, automobile repacking, etc., which are interactive and social, and have a high correlation with people's daily life. Vehicle is much more than a transport, the relationship between automobile and society, can incarnate more connotation of automobile culture.

\section{B. Teaching method: the teaching mode is relatively monotonous}

At present, the majorities of "automobile culture" courses are taught in multimedia classrooms, and supplemented by relevant experimental equipment or external practical visits. The teaching mode is also mainly the teacher teaching with PPT. Such teaching method is simple and practicable, but too monotonous. The main purpose of elective students is to get the prescribed course credits; they are difficult to have interest in such a monotonous course. Therefore, it is very necessary to optimize the teaching mode and improve students' interest and participation.

We flexibly adopt different teaching methods for the different knowledge plates of course contents.

(1) Automobile basic knowledge section, which consists of automotive structures and principles. Due to its specialization, this section is mainly taught by teachers. Since it is a public course, the structures and principles of the car should be easily understood. By the mature virtual animation technology, the automobile components and working principles can be visualized vividly, and also can be observed by visiting laboratory physical artifacts or vehicle anatomical model in the museum.

(2) Automobile brands, developing history, classical cars, the legendary of the automobile brands' founders and models' designers. This section is most interesting and understandable for students. In this part, all students are divided into groups, and one group consists of three students, each group chooses a favorite auto brand and model, collects relevant materials and makes a PPT, and makes a presentation to everyone in class (as shown in FIGURE I). This method focuses on cultivating the students' active learning ability, team cooperation ability, information integration ability, language expression ability, the scene atmosphere controlling ability, etc., and then the teacher reviews their content and performance.

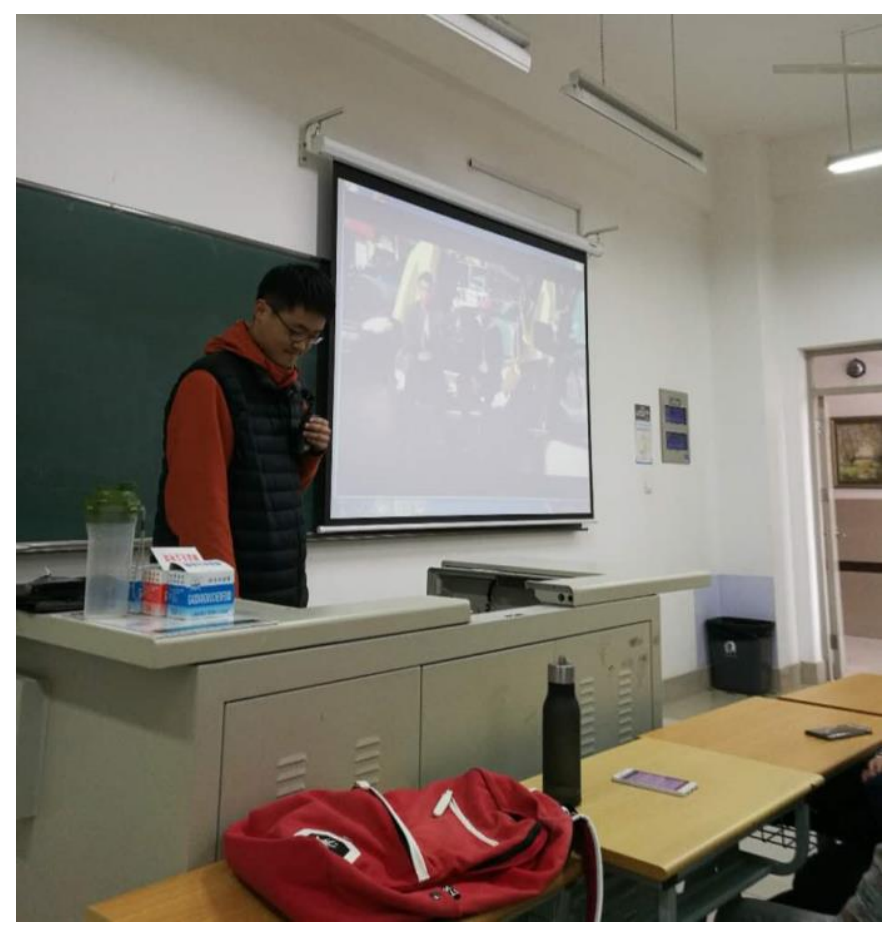

Fig. 1 Presentation in class 
(3) For vehicle and society, relevant contents are broad and abstract. This section is open and future-oriented. Therefore, we have set two main lines: one is the technical main line which focuses on the technology developing trend of the automobile; another is the cultural thread, focusing on the rapid development of automobile technology to bring about changes in people's lives, including new ways of travelling, entertainment and social norms. We adopted the mode of theme discussion, teacher would guide and encourage students to think deeply and independtly, exercise their ability of expression. This is an open mode of teaching.

\section{Assessment method: not scientific and reasonable}

Course assessment is an important link in the teaching process, and has important influence on the learning enthusiasm of students and the effect of classroom teaching, scientific and reasonable assessment method can promote the cultivation of students' active learning ability, thinking ability, innovation ability. Generally, in the "automobile culture" course, every student should submit a thesis or finish a test paper for the assessment, but most elective students are freshman or sophomore, they do not have the basic ability to write a thesis. To cope with the examination, they would download a paper from Internet. This kind of assessment cannot promote independent thinking of students. The examination method of test paper is single, rigid and inflexible; it is easy for students to get high score by rote memorization and temporary raids, cannot access the true level of students.

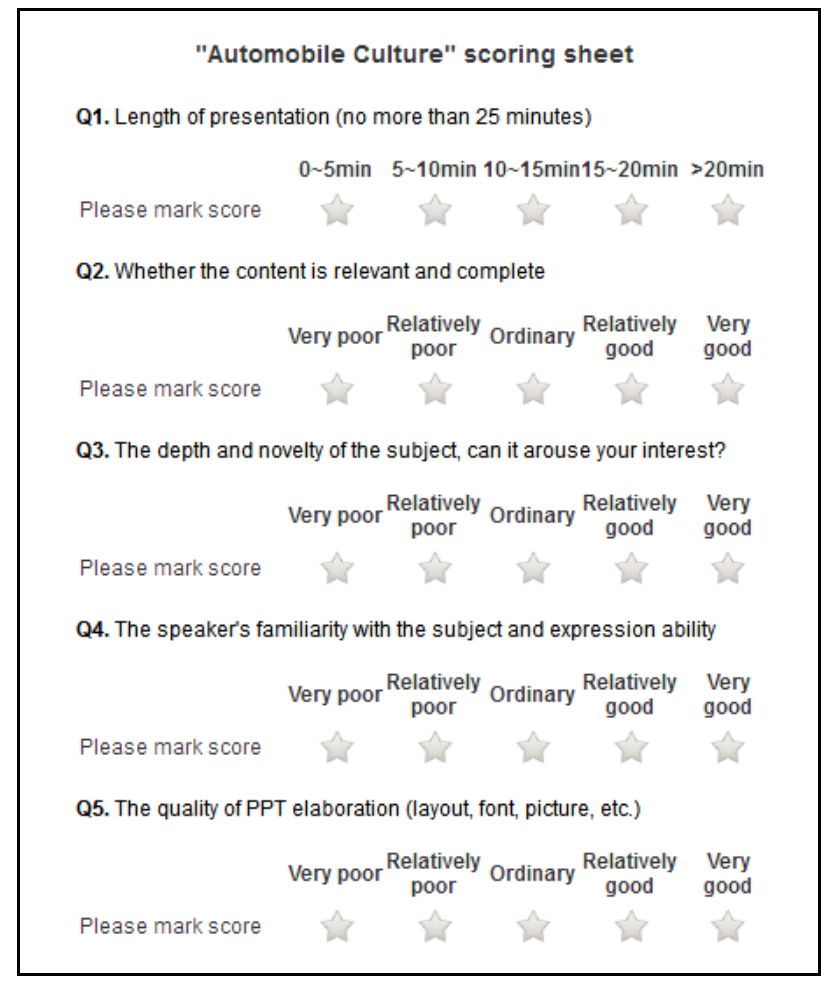

Fig. 2 Scoring sheet

In this curriculum, we had adopted a comprehensive assessment method. First, each group had to finish the presentation in class. We had built a WeChat group including all the teachers and students in class, and designed a scoring sheet (as shown in TABLE I) which was shared in the WeChat group. When a group finished their presentation, everyone used his/her mobile phone, logon to WeChat, and got into the WeChat group to fill in and submit the scoring sheet on line. Finally, the teacher summarized the scores in the background, and taken the average score as the assessment of each group. The overall grade of each student will be based on the assessment of the group's performance and regular attendance record; an appropriate gain will be made according to the class discussion. This assessment method is of strong operability and impartiality, and can evaluate students' performance in all aspects.

\section{TEACHING TEAM BUILDING}

The key to the teaching lies in the teachers; the teachers' cultural quality and professional level directly influence the teaching effect. Therefore, it is very important to establish a high-level teaching staff for curriculum innovation and construction. A common way is to build a teaching team including professional teachers, experimentalists and engineers. In modular teaching, each teacher takes charge his/her adept content according to his/her expertise [6]. This kind of team building approach is well conceived, but relatively inoperable, and it is difficult to integrate a strong team with so many people in a general education course. While students cannot easily adapt to different teaching styles of multiple teachers, it might cause confusion. Therefore, we had set up a three-person teaching team that includes professional teachers and experimentalists. Members of the teaching team constantly improve their professional level according to the demand of the course, and can consult senior teachers and other professional staff in unfamiliar areas. Teachers own learning process, for students, is also an important demonstration. Through the construction of curriculum, on the one hand, the curriculum teaching system has been comprehensively reformed and optimized, and on the other hand, the teaching level of the teachers' team has been continuously improved.

\section{CONCLUSIONS}

The practice of "Automobile Culture" is proved that can effectively promote the comprehensive quality of college students and realized the integration of the popularization of science and technology and the promotion of humanistic quality. "Automobile Culture" as a new curriculum, there is more improvements would be carried on teaching contents, teaching methods and assessment methods, and need to draw more attention and be popularized further. The technical security connotation and the strong fashion culture of the automobile industry make it significant and necessary to offer the "automobile culture" curriculum. "Automobile culture" as a new course, it also need to improve in aspects such as teaching contents, teaching methods and examining method, need to draw more attention and be popularized further, while the security connotation and strong fashion culture of automobile industry itself, had decided the importance and necessity to open an " Automobile Culture " curriculum. 


\section{ACKNOWLEDGMENT}

Project supported by the Foundation of Shanghai Dianji University (No. A1-0224-17-010-19 and No. A1-0224-17-012$10)$.

\section{REFERENCES}

[1] Jinyu Qu, Guojun Ren. Automobile culture [M]. Beijing: China Machine Press, 2015.

[2] Yongcheng Lin, Meihua Li. Automobile culture [M]. Beijing: China Renmin University Press, 2008.
[3] China news network. China's auto sales volume was the largest in the world for eight consecutive years in 2016 [EB/OL].
[E http://news.xinhuanet.com/auto/2017 01/13/c_1120301685.htm, 2017-113.

[4] Jun Lu. Exploration on the teaching mode of automobile culture course based on interest orientation [J]. Course Teaching Methods $>$ Teaching, 2016, (18): 124-125.

[5] Jianzhen Zhang, Jinsong Li. The reformation and thinking of "automobile culture" in colleges [J]. Course Education Research, 2015, (2): 56-57.

[6] Yingying Chen, Ning Yu, Ying Yang. The exploration and practice of quality-orientated teaching in "automobile culture" $[\mathrm{J}]$. Education Teaching Forum, 2016, 2(6): 159-160. 